\title{
ARSENIC REMOVAL FROM DRINKING WATER USING FLYASH AS
}

\section{AN ADSORBENT}

\author{
C R Ramakrishnaiah ${ }^{1}$, Deepika B Naikar ${ }^{2}$ \\ ${ }^{I}$ Associate Professor, Department of Civil Engineering, BMS College of Engineering, Bengaluru, Karnataka, India \\ ${ }^{2} M$-Tech Scholar, Department of Civil Engineering, BMS College of Engineering, Bengaluru, Karnataka, India
}

\begin{abstract}
Nowadays water pollution has become a major problem that is being faced by the human kind. Among various pollutants present in water, arsenic is gaining much importance because of the toxicity of its compounds. Hence it is very much necessary to find the best suitable technique for removal of arsenic from drinking water. In the present study, the removal of Arsenic from synthetic sample on coated fly ash has been carried out at room temperature $32 \pm 1^{\circ} C$. Initially raw fly ash was used for the experiment and it was seen that the residual arsenic concentration increased hencebatch tests were conducted for the removal of Arsenic on iron sulphate coated fly ash for optimum parameters such as dosage, $\mathrm{pH}$, time, initial concentration and agitation rate. The maximum removal efficiency was obtained at an optimum dosage of $0.5 \mathrm{gms}$. It was found that $100 \%$ removal can be achieved at slightly alkaline $\mathrm{pH}$ condition. The optimum time, initial concentration and agitation rate were found to be $15 \mathrm{mins}, 140 \mu \mathrm{g} / \mathrm{l}$ and $150 \mathrm{RPM}$ respectively.
\end{abstract}

Keywords: Arsenic, Adsorption, Iron Sulphate coated Fly Ash.

\section{INTRODUCTION}

Arsenic is the 20th most abundant element found in the earth's crust. It occupies nearly $0.00005 \%$ of the entire earth's surface [2]. Arsenic occurs naturally and sometimes can be produced by anthropogenic sources such as mining, industrial and agricultural activities. It is found naturally in the geologic substrate and also can be produced during volcanic eruptions. Arsenic occurs in organic and in-organic forms. It is present in the organic form in food in small amount which is required for the body. In natural waters, it is present in the in-organic form namely As (III) and As (V). These two ions namely, arsenic trioxide and arsenic pentoxide are either naturally occurring or byproducts of industrial waste. The predominant species for As (III) are $\mathrm{H}_{3} \mathrm{AsO}_{3}$ and for $\mathrm{As}(\mathrm{V})$ are $\mathrm{H}_{2} \mathrm{AsO}^{4-}$ and $\mathrm{HAsO}_{4}{ }^{2-}$. These chemicals can badly affect human health[10]when they are consumed in large amount. The ground water at various locations in Bangladesh, West Bengal, some parts of Bihar\& Karnataka in India, has been noticed to be contaminated with Arsenic (As) in excess of its permissible limit. Recently 14 out of 20 villages at Surpur taluq of Yadgir district, Karnataka state (India) has been found to be affected by Arsenic content.Several incidents have demonstrated that Arsenic in water may be carcinogenic. Acute poisoning by Arsenic involves the central nervous system leading to coma and for doses of 70-80 mg to death. The gastro-intestinal tract, nervous system, the respiratory tract, and the skin can be severely affected [4]. It is recommended that, when water is found to contain Arsenic in excess of $0.01 \mathrm{mg} / \mathrm{L}$ (W.H.O), the water is considered to be unfit for drinking. Arsenic can be removed by many conventional and non-conventional methods. Adsorption is used widely to remove Arsenic metal from water and industrial wastewater. Adsorption offers significant advantages like low cost, availability, profitability, ease of operation and efficiency, in comparison with conventional methods especially from economical and environmental points of view. Many attempts have been made to remove arsenic from water using various adsorbents.

Fly ash is a by-product that is produced by coal fired thermal power plant. From literature review it can be concluded that fly ash has sorptive properties with regard to heavy metals [3].And it was also found that iron containing adsorbents were effective in arsenic removal from aqueous solution hencefly ash coated with iron sulphate was used in the present study [5].

\section{MATERIALS AND METHODS}

\subsection{Materials}

Fly ash was obtained from Raichur Thermal Power Plant and the chemical properties depend on the source, and method of combustion. The main contents of fly ash are silica and alminosilicates. Particle size should be given due consideration in the process of adsorption hence fly ash used was 300 micron passing and 150 micron retained. The fly ash was coated with iron sulphate and then used.

The instruments used for the experimental work are Electronic Balance, $\mathrm{pH}$ meter, Magnetic Stirrer,Atomic Absorption Spectrophotometer,and Gyro shaker which were used from the college laboratory and all the glass wares used were made up of Borosilicate.

\subsubsection{Chemicals}

Arsenic stock solutions were prepared in distilled water using arsenic trioxide. Arsenic working solutions were 
freshly prepared by diluting arsenic stock solutions with distilled water. $\mathrm{H}_{2} \mathrm{SO}_{4}$ and $\mathrm{NaOH}(0.1 \mathrm{~N})$ were used for adjusting the $\mathrm{pH}$ of the arsenic solution.

\subsection{Methods}

Initially raw fly ash was used for the removal of arsenic from synthetic solution. $100 \mathrm{ml}$ of sample containing $10 \mu \mathrm{g} / \mathrm{l}$ arsenic was tested at different adsorbent dosage. After the experimental studies, it was found that arsenic concentration in the effluent increased hence there was a need to coat the fly ash with iron sulphate since iron containing adsorbents were effective in arsenic removal.

\subsubsection{Preparation of Coated Fly Ash}

$100 \mathrm{gms}$ of fly ash was mixed with $600 \mathrm{ml}$ distilled water containing $156.75 \mathrm{gms}$ of ferrous sulphate. The mixture was stirred in a magnetic stirrer for about 1hour, then after $15 \mathrm{mins}$ of settling, the solution was decanted and $100 \mathrm{ml}$ of distilled water containing $2 \mathrm{gms} \mathrm{NaOH}$ was added. Again the mixture was stirred for 5 mins, then after 15 mins of settling, it is again decanted and kept 24hours for drying allowing for oxidation of the iron coating. After 24hours of drying, coated fly ash is obtained which is used for further batch studies $[1,8,9]$.

\subsubsection{Determination of Optimum Dosage of}

\section{Adsorbent}

To determine the optimum dosage of coated fly ash, it was added to the beaker in different dosage varying from ( $0.1 \mathrm{gms}, 0.2 \mathrm{gms}$, and $0.3 \mathrm{gms}$ and up to $2.0 \mathrm{gms})$, containing $100 \mathrm{~mL}$ solution with arsenic concentration of $100 \mu \mathrm{g} / \mathrm{L}$. The solution in the beaker was subjected to stirring for $30 \mathrm{mins}$, filtered and analyzed for residual arsenic concentration. The dosage which gives minimum residual concentration is chosen as optimum dosage.

\subsubsection{Selection of Optimum Contact Time}

Contact time is an important parameter which strongly influences the adsorption. To study the effect of contact time, $100 \mathrm{~mL}$ of $100 \mu \mathrm{g} / \mathrm{L}$ arsenic solution was mixed with $0.5 \mathrm{gms}$ of coated fly ash, stirred in a rotary shaker at different contact times varying from $(2 \mathrm{mins}$, $4 \mathrm{mins}$ up-to 30mins). Then filtrate was analyzed for arsenic concentration using Atomic Absorption Spectrophotometer. The lowest contact time at which maximum arsenic removal takes place was taken as optimum contact time.

\subsubsection{Selection of Optimum pH}

$\mathrm{pH}$ is another important parameter on which the adsorption is strongly dependent. The effect of $\mathrm{pH}$ on arsenic adsorption was studied by performing adsorption tests at different initial $\mathrm{pH}$ values. i.e. from 2.0 to 10 . The $\mathrm{pH}$ of solution was adjusted by using $\mathrm{HNO}_{3}$ or $0.1 \mathrm{~N} \mathrm{NaOH}$. The $\mathrm{pH}$ which gives maximum removal of arsenic was chose as optimum $\mathrm{pH}$.

\subsubsection{Selection of Optimum Initial Concentration}

The rate of adsorption also varies with respect to initial concentration of arsenic in the water. To find the optimum initial concentration, studies were conducted by varying the initial concentration from $(10 \mu \mathrm{g} / \mathrm{L}, 20 \mu \mathrm{g} / \mathrm{L}$ and up-to $300 \mu \mathrm{g} / \mathrm{L})$. $\quad 0.5 \mathrm{gms}$ of coated fly ash was added in $100 \mathrm{ml}$ solution at $\mathrm{pH}$ of 10 and the contact time maintained was 15mins. Then the filtrate was used to find the residual arsenic.

\subsubsection{Selection of Optimum Agitation Rate}

To find the optimum agitation rate, $0.5 \mathrm{gms}$ of coated fly ash was added in $100 \mathrm{ml}$ of solution containing $140 \mu \mathrm{g} / \mathrm{l}$ and it was stirred in a rotary shaker at different agitation rate. Later the solution was filtered and analyzed for the residual arsenic concentration. The minimal agitation rate at which higher percentage of arsenic was removed is chose as optimum agitation rate.

\section{RESULTS AND DISCUSSIONS}

\subsection{Effect of Adsorbent Dosage}

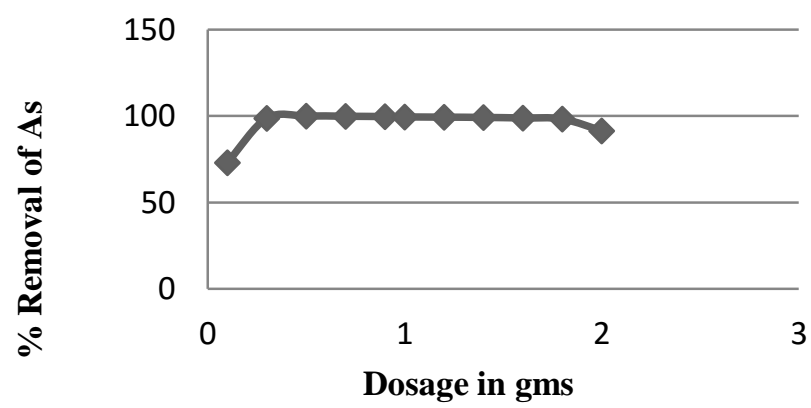

Fig-1: Effect of adsorbent dosage

The Effect of dosage of adsorbent was studied and graph of percentage of arsenic removal versus dosage was plotted as shown in Fig.1. From the graph it is observed that, as the dosage of coated fly ash increases, arsenic removal increases and attains maximum later. This is mainly due to the large contact surface area and adsorption sites available for adsorption.Later the coated fly ash gets saturated and the removal efficiency of the adsorbent decreases. Another reason is as the dosage increases, there are chances of aggregation of fly ash molecules which leads to lesser surface area resulting in reduction of removal efficiency. The dosage, at which maximum removal is attained, is taken as maximum dosage. The removal efficiency was just $70 \%$ at a dosage of $0.1 \mathrm{gms}$ and it increased to $100 \%$ at a dosage of $0.5 \mathrm{gms}$.

\subsection{Effect of pH}

Effect of $\mathrm{pH}$ was studied and graph of percentage of arsenic removal versus $\mathrm{pH}$ was plotted as shown in Fig.2. 


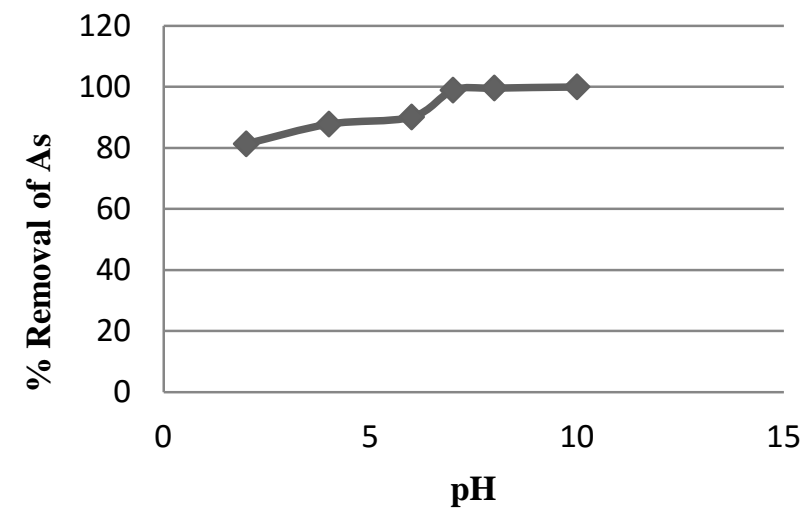

Fig - 2: Effect of $\mathrm{pH}$

From the graph it is observed that, arsenic is removed more effectively in slight alkaline range. The removal efficiency of arsenic using coated fly ash was $100 \%$ at a $\mathrm{pH}$ range of 810. From the earlier studies the maximum adsorption of arsenic was obtained at a $\mathrm{pH}$ range of 7-9[3] and therefore the explanations of how $\mathrm{pH}$ affects arsenic adsorption can be applied to this adsorbent $[6,7]$.

\subsection{Effect of Contact Time}

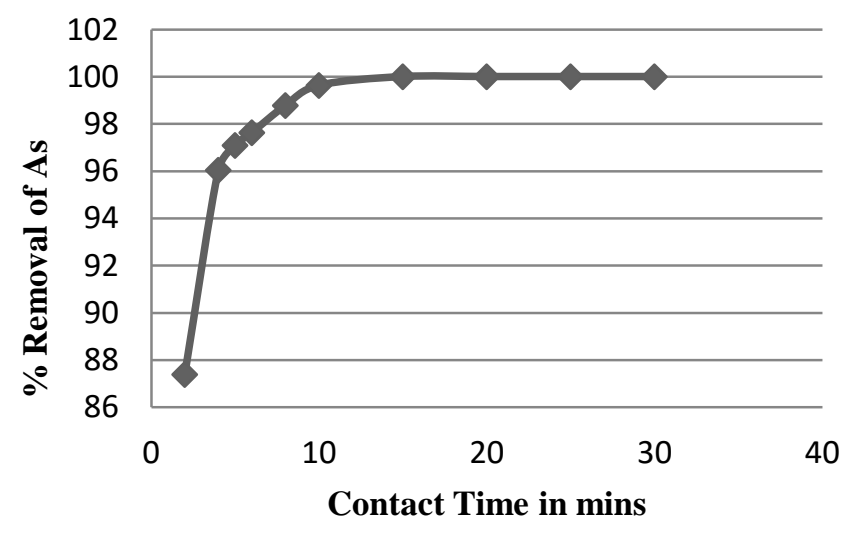

Fig - 3: Effect of Contact Time

Effect of contact time was studied and graph of percentage of arsenic removal versus contact time in minutes was plotted as shown in Figure.3. From the graph it is evident that the extent of arsenic adsorption increases with increase in time. The adsorption curves are characterized by sharp rise in initial stage and decreases near equilibrium. The removal efficiency of arsenic by using coated fly ash was $100 \%$ for a contact time of $15 \mathrm{mins}$.

\subsection{Effect of Initial Concentration}

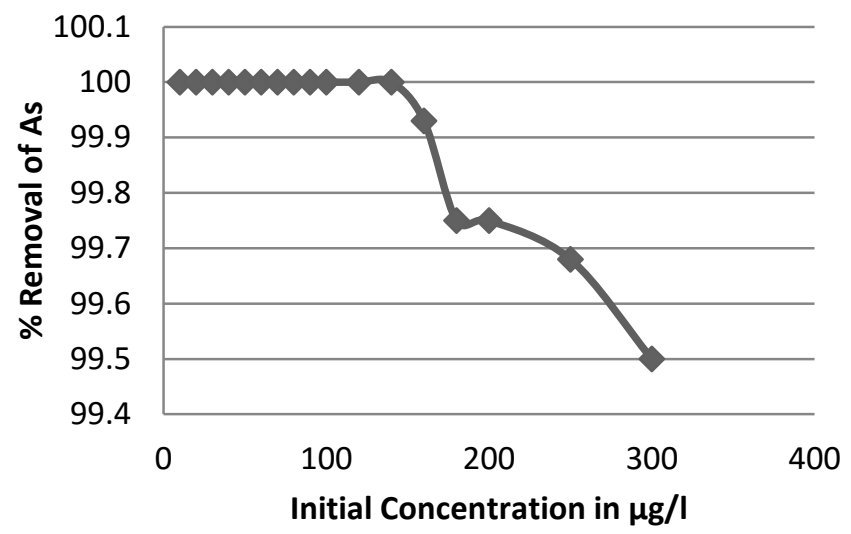

Fig - 4: Effect of Initial Concentration

The effect of initial concentration was studied and a graph was plotted as shown in the figure 4. From the graph, we can observe that $100 \%$ removal was there for $10 \mu \mathrm{g} / \mathrm{l}$ which is the maximum allowable concentration for arsenic in drinking water. As the concentration of arsenic increased, $100 \%$ removal was observed till an initial concentration of $140 \mu \mathrm{g} / \mathrm{l}$.

\subsection{Effect of Agitation Rate}

The rate of adsorption was also studied with respect to agitation rate.

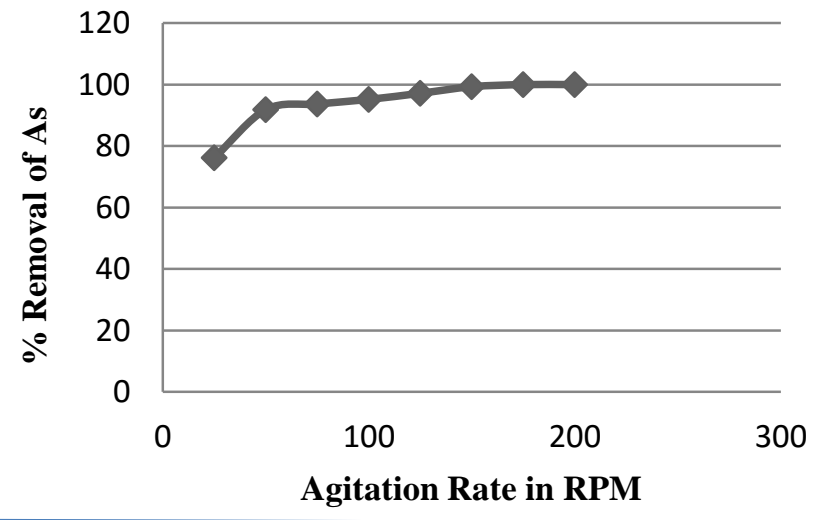

Fig - 5:Effect of Agitation Rate

After the experimental studies, a graph of percentage removal of arsenic versus agitation rate was plotted as shown in the figure.5. From the graph, it was clear that as the agitation rate increases, removal percentage also increases. The optimum agitation rate was found to be 150RPM.

\section{CONCLUSION}

- The trial study using raw fly ash showed that arsenic concentration increased in the effluent due to the presence of arsenic in the fly ash.

- Arsenic adsorption on coated fly ash was studied in batch adsorption experiments. With an initial arsenic concentration of $100 \mu \mathrm{g} / \mathrm{l}$, the effect of adsorbent 
dosage, $\mathrm{pH}$, contact time, and agitation rate were studied.

- From the experimental data, it was found that the optimum parameters were as follows:
$>$ Optimum dosage $-0.5 \mathrm{gms}$
$>$ Optimum $\mathrm{pH}-8-10$
$>$ Optimum contact time -15 minutes
$>$ Optimum initial concentration $-140 \mu \mathrm{g} / \mathrm{l}$
$>$ Optimum agitation rate $-150 \mathrm{RPM}$

- Initially rate of adsorption increases with the increase in the adsorbent dosage and later decreases on further addition of adsorbent.

- Removal efficiency increases with increase in the $\mathrm{pH}$ of the solution and it was found that $80-100 \%$ removal was achieved in the $\mathrm{pH}$ range of 3-10. Maximum percentage removal was observed at $\mathrm{pH}$ 8-10.

- Percentage removal of arsenic increased with the increase in the contact time and further increase in contact time had no effect on removal efficiency.

- As the concentration of the arsenic in the sample increases, the removal efficiency decreases.

- As the agitation rate increased, removal efficiency increased. The optimum agitation rate was found to be 150RPM.

\section{REFERENCES}

[1] Johanna L Mathieu et.al 2008, University of California, "Removing Arsenic from contaminated drinking water in rural Bangladesh: Recent Fieldwork Results and policy Implications".

[2] Ashutosh S. Vakharkar, 6-1-2005., University of South Florida ,"Adsorption studies for arsenic removal using modified chabazite".

[3] Izabela Polowczyk et.al, 2011.,czasopismo techniczne technical transactions, "Sorption Properties of Fly Ash From Brown coal Burning towards Arsenic Removal".

[4] Sneha Latha and S R Samadder, 2014, International Journel of Environmental research \& Development, "Removal of heavy metal using Rice Husk: A Review", Volume 4, Number 2, pp.165-170.

[5] Rukmini. Roy et. Al 2014, International Journla of Research in Environmental Science and Technology, "Recent Advancement in Arsenic Adsorbents: A mini Review".

[6] Le Zeng, 2004, "Arsenic Adsorption from Aqueous Solutions on an Fe(III)- Si Binary Oxide Adsorbent", Volume 39,No.3,267-275.

[7] Kelly B. Payne and Tarek M. Abdel-Fattah, Journal of Environmental Science and Health, 2005, "Adsorption of Arsenate and Arsenite by IronTreated Activated Carbon and Zeolites: Effects of pH, Temperature, and Ionic Strength" 40:723-749.

[8] Viveka D Mude et.al, International Journal of Advances in Engineering Science and Technology, "Removal of As(III) from Groundwater by Commercial Activated Carbon: Batch Study", Volume No.8, Issue No. 1, 125-134.
[9] Sang-Yoon Min, Environmental Engineerinf Research, "Removal Efficiency of Arsenic by Adsorbents having Different Type of Metal Oxides",2009, Volume 14, No. 2, pp. 134 139.

[10] M. Feroze Ahmed, Department of Civil Engineering Bangladesh University of Engineering \& Technology, Dhaka-1000, Bangladesh",An Overview of Arsenic Removal Technologies in Bangladesh and India”. 